\title{
Cognitive and Neuropsychiatric Consequences of Endocannabinoid Signaling Dysfunction
}

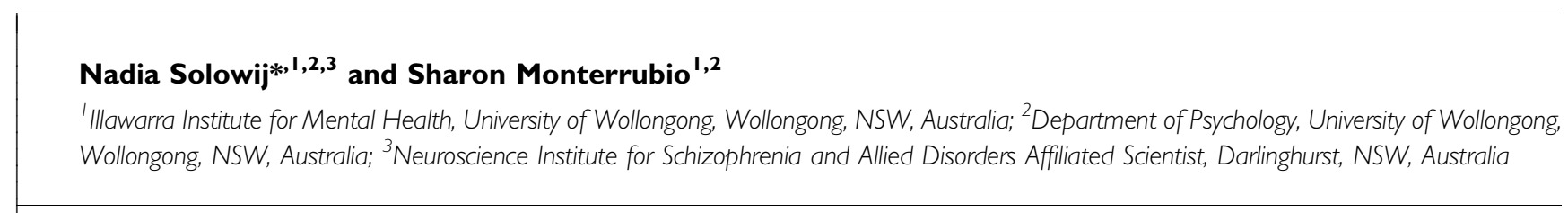

Neuropsychopharmacology (2006) 3 I, 47I -472. doi:| 0. I 038/sj.npp. 1300895

Sir

Hill et al (2005) report that cognitive deficits induced by chronic stress are associated with a downregulation of hippocampal cannabinoid receptors and reduced levels of 2-AG, an endogenous cannabinoid (eCB). Deficits were reversed by administration of an exogenous cannabinoid. They suggest that a dysfunction of the eCB signaling system may underlie stress-induced cognitive deficits. This important finding provides a missing link with studies of cognitive functioning in human cannabis users. We have previously reported a reversal of electrophysiological indices of selective attention deficits by smoked cannabis in a chronic user (Solowij et al, 1995a), who had shown inappropriate processing (deficient filtering) of irrelevant stimuli in the unintoxicated state in accord with our earlier studies of cannabis users (Solowij et al, 1991, 1995b; Solowij, 1995, 1998). Similar reversal of this filtering deficit during acute intoxication was also found in a larger sample of chronic users (unpublished data). We had also interpreted the selective attention deficits in chronic users as being due to a dysfunction of the eCB system resulting from chronic exposure to the drug. These processes of selective attention have since been shown to be regulated by excitatory and inhibitory feedback mechanisms via prefrontal cortex (PFC), anterior cingulate and hippocampus (Melara et al, 2002). A downregulation of CB1 receptors in hippocampus would disrupt the efficient functioning of the PFC in inhibiting activations to irrelevant stimuli, and similar mechanisms are proposed by Hill et al (2005) in relation to processes induced by stress.

The fine-tuning role of the eCB system in regulating cortical information processing is becoming increasingly apparent. Melis et al (2004) report a novel eCB-mediated

\footnotetext{
*Correspondence: Dr N Solowij, Department of Psychology, University of Wollongong, Wollongong, New South Wales 2522, Australia, Tel: +61 24221 3732, Fax: +61 242214163 ,

E-mail: nadia@uow.edu.au

Received 3 May 2005; accepted 9 August 2005

Online publication: 10 August 2005 at http://www.acnp.org/citations/ Npp081005050290/default.pdf
}

self-regulatory role of dopamine neurons by which they release 2-AG selectively to suppress PFC-stimulationevoked activity. They also infer that a dysfunction in the eCB system may be involved in altered stress responses and contribute to inappropriate incentive salience to irrelevant stimuli. Cannabinoids potently increase dopamine metabolism and release in PFC but repeat administration leads to a persistent anatomically selective reduction of dopamine metabolism in PFC (Verrico et al, 2003), which has now been shown to underlie attentional deficits (Verrico et al, 2004). Cannabinoids also have a profound influence on learning and memory via effects on eCB-mediated hippocampal metaplasticity (Mato et al, 2004). A dysfunction in hippocampal eCB signaling, and resultant effects on related circuitry, may underlie impairments of learning and memory in chronic cannabis users (Solowij et al, 2002).

Hill et al (2005) discuss their findings in terms of direct $\mathrm{CB}$ ligand/receptor interactions, other neurotransmitters, glucocorticoids, leptin, brain region-specific mechanisms, and other physiological changes that accompany stress. Another putative mechanism may involve fatty acids. We have recently reported on peripheral fatty acid alterations in relation to stress that were differentially evident in schizophrenia patients according to cannabis use history (Monterrubio et al, in press). Only former cannabis users with schizophrenia showed a strong positive correlation between stress and linoleic acid levels and inverse correlations between arachidonic acid and fatty acid precursors of lipid signalers that interact with anandamide. Evidence for a dysfunctional eCB system in schizophrenia has been mounting (D'Souza et al, 2005; Giuffrida et al, 2004) and our findings contribute to evidence linking eCB abnormalities, cannabis use and stress in schizophrenia. Therapeutic modulation of this system for neuropsychiatric and substance use disorders is promising.

\section{REFERENCES}

D'Souza DC, Abi-Saab WM, Madonick S, Forselius-Bielen K, Doersch A, Braley G et al (2005). Delta-9-tetrahydrocannabinol effects in schizophrenia: implications for cognition, psychosis, and addiction. Biol Psychiatry 57: 594-608. 
Giuffrida A, Leweke FM, Gerth CW, Schreiber D, Koethe D, Faulhaber J et al (2004). Cerebrospinal anandamide levels are elevated in acute schizophrenia and are inversely correlated with psychotic symptoms. Neuropsychopharmacology 29: 2108-2114.

Hill MN, Patel S, Carrier EJ, Rademacher DJ, Ormerod BK, Hillard CJ et al (2005). Downregulation of endocannabinoid signaling in the hippocampus following chronic unpredictable stress. Neuropsychopharmacology 30: 508-515.

Mato S, Chevaleyre V, Robbe D, Pazos A, Castillo PE, Manzoni OJ (2004). A single in vivo exposure to $\triangle 9 T H C$ blocks endocannabinoid-mediated synaptic plasticity. Nat Neurosci 7: 585-586.

Melara RD, Rao A, Tong Y (2002). The duality of selection: excitatory and inhibitory processes in auditory selective attention. J Exp Psych Hum Perc Perf 28: 279-306.

Melis M, Perra S, Muntoni AL, Pillola G, Lutz B, Marsicano G et al (2004). Prefrontal cortex stimulation induces 2-arachidonoylglycerol-mediated suppression of excitation in dopamine neurons. J Neuroscience 24: 10707-10715.

Monterrubio S, Solowij N, Meyer B, Turner N (in press). Fatty acid relationships in former cannabis users with schizophrenia. Prog Neuropsychopharm Biol Psychiatry.

Solowij N (1995). Do cognitive impairments recover following cessation of cannabis use? Life Sci 56: 2119-2126.
Solowij N (1998). Cannabis and Cognitive Functioning. Cambridge University Press: Cambridge.

Solowij N, Grenyer BFS, Chesher G, Lewis J (1995a). Biopsychosocial changes associated with cessation of cannabis use: a single case study of acute and chronic cognitive effects, withdrawal and treatment. Life Sci 56: 2127-2134.

Solowij N, Michie PT, Fox AM (1991). Effects of long term cannabis use on selective attention: An event-related potential study. Pharmacol Biochem Beh 40: 683-688.

Solowij N, Michie PT, Fox AM (1995b). Differential impairments of selective attention due to frequency and duration of cannabis use. Biol Psychiatry 37: 731-739.

Solowij N, Stephens RS, Roffman RA, Babor T, Kadden R, Miller M et al (2002). Cognitive functioning of long term heavy cannabis users seeking treatment. JAMA 287: 1123-1131.

Verrico CD, Jentsch JD, Roth RH (2003). A persistent and anatomically selective reduction in prefrontal cortical dopamine metabolism after repeated, intermittent cannabinoid administration to rats. Synapse 49: 61-66.

Verrico CD, Jentsch JD, Roth RH, Taylor JR (2004). Repeated, intermittent $\Delta^{9}$-tetrahydrocannabinol administration to rats impairs acquisition and performance of a test of visuospatial divided attention. Neuropsychopharmacology 29: 522-529. 